\title{
Prevalence and Psychiatric Risk Factors of Excessive Internet Use among Northern Bangladeshi Job-Seeking Graduate Students: A Pilot Study
}

\author{
Mohammed A. Mamun ${ }^{1,2} \cdot$ Md. Abdur Rafi $^{2,3}$ A. H. M. Shamim Al Mamun ${ }^{1,2}$ • \\ Md. Zahid Hasan ${ }^{1,2} \cdot$ Konok Akter ${ }^{1,2} \cdot$ Kamrul Hsan $^{1,2,4}$. Mark D. Griffiths ${ }^{5}$ (iD
}

Published online: 18 March 2019

(C) The Author(s) 2019

\begin{abstract}
Although internet addiction (IA) has been the subject of research in many countries, it is poorly studied in Bangladesh, and previous studies in the country have not examined potential mental health risk factors in relation to the development of IA. The present pilot study attempted to assess the prevalence and associated risk factors of IA among a convenience sample of recently graduated university students actively looking for a job $(N=284)$ from July to October 2018 in Rajshahi (a city in Bangladesh). The measures included socio-demographic and behavioral variables, the Internet Addiction Test (IAT), and the Depression, Anxiety, and Stress Scale. Surprisingly, no cases of IA were identified in the sample (i.e., the prevalence rate of IA was $0 \%$ ) which may have been a consequence of the specific population sampled. A total of $3.9 \%$ of the participants $(n=11)$ were classified as excessive users ( $\geq 60$ in IAT). Using regression analysis, the risk factors for excessive internet use were spending more time online ( $>5$ h daily) and experiencing psychiatric conditions (i.e., depression, stress). It is hoped the present pilot study will facilitate further study in Bangladesh with a more in-depth focus on the socio-demographic and psychiatric morbidities in excessive and problematic internet use. It is also speculated that job-seeking may be a situational protective risk factor for developing IA.
\end{abstract}

Keywords Internet addiction · Excessive internet use - Online addiction · Addiction comorbidity · Bangladeshi student health

Mark D. Griffiths

mark.griffiths@ntu.ac.uk

1 Department of Public Health \& Informatics, Jahangirnagar University, Savar, Dhaka, Bangladesh

2 Undergraduate Research Organization, Dhaka, Bangladesh

3 Rajshahi Medical College, Rajshahi, Bangladesh

4 Institute of Allergy and Clinical Immunology of Bangladesh (IACIB), Savar, Dhaka, Bangladesh

5 International Gaming Research Unit, Psychology Department, Nottingham Trent University, 50 Shakespeare Street, Nottingham NG1 4FQ, UK 


\section{Introduction}

Internet use has been increased rapidly around the world along with reports of excessive and uncontrolled use among a minority of internet users. Such problematic use has been termed as "internet addiction" (Young 1998), and is sometimes based on the core criteria of behavioral addictions such as salience, mood modification, tolerance, withdrawal symptoms, conflict, and relapse (Griffiths 1996, 1998, 2005). IA has been conceptualized as an impulse-control disorder that shares characteristics with behavioral addictions and has become increasingly relevant in many parts of the world (Dieris-Hirche et al. 2017).

Internet addiction has been associated with a number of socio-demographic variables, time and patterns spent online, psychosocial factors, and comorbid symptoms/disorders (Carli et al. 2013; Kuss et al. 2017; Kuss et al. 2014). Common predictors of IA include socio-demographic factors (e.g., age, gender, residence, relationship status), as well as other factors including sleep disturbance, lack of physical activity, and job status (Afrin et al. 2017; Bener et al. 2018; Bener and Bhugra 2013; Islam and Hossin 2016; Lai and Kwan 2017; Vigna-Taglianti et al. 2017; Younes et al. 2016). Generalized IA has also been associated with a wide variety of excessive online behaviors including using the internet for academic purposes, communicating via social networking sites, online gaming, accessing online movie and music sites, viewing online sexually explicit materials and pornography, online gambling, and online shopping (Bener et al. 2018; Hoare et al. 2017; Simcharoen et al. 2018; Vigna-Taglianti et al. 2017).

Previous studies have also demonstrated a high comorbidity of IA with psychiatric symptoms and mental impairments (Lai and Kwan 2017). Most studies regarding IA and psychopathology (i.e., depression, anxiety, stress) have indicated such associations and comorbidities (Dieris-Hirche et al. 2017; Ko et al. 2014; Mak et al. 2014; Ostovar et al. 2016; Younes et al. 2016). Based on these past findings, the self-medication hypothesis of behavioral addiction appears to be associated with the development and maintenance of IA as a result of an individual's attempts to "self-treat" with their stress, anxiety, and depression (Allison et al. 2006; Khantzian 1997; Kuss et al. 2017).

IA has been considered to be a public health problem (Bener and Bhugra 2013) and has been studied more in developed and developing countries. In a European study including nine countries, the prevalence rate of problematic internet use ranged between 14 and 55\% (Laconi et al. 2018). A study comprising six Asian countries found that the prevalence rate of IA using IAT with a cutoff score of $\geq 70$ ranged between 14 and $51 \%$ (Mak et al. 2014). The global prevalence of problematic Internet use, using different criteria and tools, has been shown to range between 0.03 to $36.7 \%$ (Adiele and Olatokun 2014; Afrin et al. 2017; Dalbudak et al. 2014; Dieris-Hirche et al. 2017; Islam and Hossin 2016; Karim and Nigar 2014; Lee et al. 2016; Simcharoen et al. 2018; Uddin et al. 2016; Younes et al. 2016).

In Bangladesh, the "Digital Bangladesh" movement was launched to promote internet technology by the current government. As a result, the number of internet subscribers has increased during past few years after launching the movement. Within a single year, there were 12.677 million new users between October 2017 and 2018 and now totals 92,466 million users (BTRC 2018). Moreover, the capital of the country comprises 20 million Facebook users and it has been ranked second among cities globally (Mamun and Griffiths 2019a). Consequently, it is likely that online addictive behaviors have increased in Bangladesh over recent years. Although a few studies have been conducted in Bangladesh cities such as Chattagram (among high school students) (Afrin et al. 2017) 
and Dhaka (among university current students) (Islam and Hossin 2016; Karim and Nigar 2014; Uddin et al. 2016), problematic Internet use among recent graduate job seekers outside of Dhaka city have yet to be studied. Recent graduates are also an interesting population to study in this context because it is not known whether such a group would be more prone to IA (because they may have lots of spare time having just finished their educational studies but not yet in full-time employment) or less prone to IA (because they may be spending lots of time looking for full-time employment).

Furthermore, mental health issues (e.g., depression, anxiety, and stress) regarding problematic Internet use research were not examined in previous Bangladeshi studies, although one study referred the relationship between mental health issues (psychological distress and depression) and IA (Uddin et al. 2016). There was also a recent review of IA studies carried out in Bangladesh (i.e., Mamun and Griffiths 2019b) recommending that more research in the country was needed particularly. Consequently, the present study assessed the prevalence of excessive internet use (EIU), and its associated risk factors (i.e., socio-demographics, internet usage time, and symptoms of depression, anxiety, and stress) among recent university graduates who were seeking jobs in Rajshahi (a city in Bangladesh).

\section{Methods}

\section{Participants and Procedure}

The present study is cross-sectional and was conducted using a convenience sample of recently graduated university students actively looking for a job in three job preparation coaching centers in Rajshahi, Bangladesh. The study duration was from July to October 2018. A total of 389 individuals were approached to participate in an offline survey within the coaching centers. Data were collected from 284 participants (73\% response rate; 131 males and 153 females with an average age of 24.12 years $(\mathrm{SD} \pm 1.55)$.

\section{Statistical Analysis}

Data were analyzed using Statistical Package for Social Science (SPSS) version 22.0. The final analysis included descriptive statistics (e.g., frequencies, percentages, means, and chi-square test and Fisher's exact test). Categorical variables were compared between two groups (excessive Internet users vs. non-excessive Internet users) using chi-square and Fisher's exact tests. Regression analyses were performed with SPSS 22.0. All variables were entered into the binary logistic regression model with EIU as the dependent variable. The results of logistic regression were interpreted with $95 \%$ confidence intervals.

\section{Ethics}

All study procedures were carried out following the guidelines of the Helsinki Declaration. The study conformed to the Institutional Review Board's requirements (of Institute of Allergy and Clinical Immunology of Bangladesh [IACIB]). Informed consent was obtained from participants prior to participating in the study. Anonymity and confidentiality of data were ensured, and all participants were provided with information about the nature and purpose of the study, the procedure, and the right to withdraw their data at any time. 


\section{Measures}

\section{Socio-demographic Measures}

Socio-demographic information was collected concerning age, gender, residence (city or village), relationship status (i.e., single or in a relationship (married and non-married)), and socio-economic status. Upper class families were defined as those having a monthly income of 20,001 BDT and above. Middle class families were defined as having a monthly income of 10,001 to 20,000 BDT, and lower class families were defined as those having a family income of less than 10,000 BDT (Begum et al. 2017). For educational status, the institute of graduation (public university or college) was asked. Current job status (yes or no response) was also asked.

\section{Behavioral Factors}

For basic behavioral factors, the present study asked a few questions related to lifestyle. Participants were asked if they smoked cigarettes (yes/no) and whether they engaged in moderate physical activities such as exercise, walking, playing a game, cycling, swimming, or any other activity lasting at least $30 \mathrm{~min}$ every day. As for sleep duration, respondents were asked to report their average typical sleep duration as either normal (6-7 h), short $(<6 \mathrm{~h})$, or long $(>7 \mathrm{~h})$. They were also asked about how long they spent online daily including both work and leisure.

\section{Internet Addiction Test}

To assess internet addiction, the IAT, developed by Young (1998), was administered. The IAT comprises 20 items scored on a 5-point scale from rarely (1) to always (5). The total score of the IAT ranges from 20 to 100 . In the present study, the participants were categorized into two groups according to the IAT scores. These were excessive Internet users (scores with $\geq 60$ in IAT) and non-excessive Internet users (score $<60$ ). Adequate and acceptable reliability and validity have been demonstrated for the scale previously (Adiele and Olatokun 2014; Simcharoen et al. 2018). Very good internal consistency was obtained in the present sample (Cronbach's $\alpha=0.87$ ).

\section{Depression, Anxiety, and Stress Scale}

The DASS is a self-report scale for accessing depression, anxiety, and stress (Lovibond and Lovibond 1995). This scale comprises 21 items on a four-point Likert scale ranging from never (0) to always (3) and provides scores on three subscales all containing seven items each (i.e., depression, anxiety, and stress). In the present study, those scoring moderate to very severe were assessed as experiencing of depression ( $\geq 14$ on depression subscale), anxiety ( $\geq 15$ on anxiety subscale), and stress ( $\geq 19$ on stress subscale). The DASS are well-established psychometric properties in non-clinical samples (Ostovar et al. 2016). Previously acceptable internal consistency has been obtained for the depression, anxiety, and stress subscales, as well as the overall scale (Alim et al. 2017; Ostovar et al. 2016). For the present study, the Cronbach's alphas for the depression, anxiety, and stress subscales were $0.77,0.78$, and 0.83 , and the overall Cronbach's $\alpha$ was 0.91 . 


\section{Results}

The participants' characteristics were shown in Table 1. In total, $46.1 \%$ were males and $53.9 \%$ were females. Among the socio-demographics, most of the participants came from a village area $(79.9 \%)$, were not in a relationship $(69.7 \%)$, and came from a middle class family $(58.5 \%)$. Of the behavioral variables, $89.1 \%$ of the participants were non-smokers, $73.9 \%$ did not perform any type of daily physical activity, and $62.8 \%$ were normal sleepers (6-7

Table 1 Distribution of variables of the respondents by excessive internet use

\begin{tabular}{|c|c|c|c|c|c|}
\hline Variables & Total $284 ; n(\%)$ & Excessive internet use; yes (\%) & $X^{2}$ test value & df & $p$ value \\
\hline \multicolumn{6}{|l|}{ Gender } \\
\hline Male & $131(46.1)$ & $5(3.8)$ & 0.002 & 1 & 1.000 \\
\hline Female & $153(53.9)$ & $6(3.9)$ & - & - & - \\
\hline \multicolumn{6}{|l|}{ Permanent residence } \\
\hline Village area & $219(79.9)$ & $8(3.7)$ & 0.370 & 1 & 0.700 \\
\hline City area & $55(20.1)$ & $3(5.5)$ & - & - & - \\
\hline \multicolumn{6}{|l|}{ Relationship status } \\
\hline In a relationship & $80(29.9)$ & $3(6.0)$ & 0.042 & 1 & 1.000 \\
\hline Single & $198(69.7)$ & $8(4.0)$ & - & - & - \\
\hline \multicolumn{6}{|c|}{ Socio-economic status of family } \\
\hline Lower class & $51(18.0)$ & $4(7.8)$ & 5.178 & 2 & 0.042 \\
\hline Middle class & $166(58.5)$ & $3(1.8)$ & - & - & - \\
\hline Upper class & $67(23.6)$ & $4(6.0)$ & - & - & - \\
\hline \multicolumn{6}{|l|}{ Smoking status } \\
\hline Yes & $31(10.9)$ & $1(3.2)$ & 0.039 & 1 & 1.000 \\
\hline No & $253(89.1)$ & $10(4.0)$ & - & - & - \\
\hline \multicolumn{6}{|l|}{ Physical activities } \\
\hline Yes & $74(26.1)$ & $3(4.1)$ & 0.007 & 1 & 1.000 \\
\hline No & $209(73.9)$ & $8(3.8)$ & - & - & - \\
\hline \multicolumn{6}{|l|}{ Sleep quality } \\
\hline Less than normal & $51(18.1)$ & $1(2.0)$ & 2.183 & 2 & 0.399 \\
\hline Normal (6-7 h) & $177(62.8)$ & $6(3.4)$ & - & - & - \\
\hline More than normal & $54(19.1)$ & $4(7.4)$ & - & - & - \\
\hline \multicolumn{6}{|l|}{ Graduation institute } \\
\hline College & $157(55.3)$ & $7(4.5)$ & 0.323 & 1 & 0.759 \\
\hline Public university & $127(44.7)$ & $4(3.1)$ & - & - & - \\
\hline \multicolumn{6}{|l|}{ Current part-time job } \\
\hline Yes & $69(24.3)$ & $2(2.9)$ & 0.232 & 1 & 1.000 \\
\hline No & $215(75.7)$ & $9(4.2)$ & - & - & - \\
\hline \multicolumn{6}{|l|}{ Depression } \\
\hline No & $143(50.4)$ & $0(0.0)$ & 11.606 & 1 & 0.000 \\
\hline Yes & $141(49.6)$ & $11(7.8)$ & - & - & - \\
\hline \multicolumn{6}{|l|}{ Anxiety } \\
\hline No & $133(46.8)$ & $5(3.8)$ & 0.009 & 1 & 1.000 \\
\hline Yes & $151(53.2)$ & $6(4.0)$ & - & - & - \\
\hline \multicolumn{6}{|l|}{ Stress } \\
\hline No & 209 (73.6) & $3(1.4)$ & 12.633 & 1 & $<0.001$ \\
\hline Yes & $75(26.4)$ & $8(10.7)$ & - & - & - \\
\hline \multicolumn{6}{|l|}{ Online spent time/day } \\
\hline More than $5 \mathrm{~h}$ & $15(5.3)$ & $5(33.3)$ & 36.915 & 3 & $<0.001$ \\
\hline Less than $5 \mathrm{~h}$ & $269(94.7)$ & $6(2.2)$ & - & - & - \\
\hline \multicolumn{6}{|l|}{ Internet addiction test score } \\
\hline Normal user (<60 scores) & $248(96.1)$ & - & - & - & - \\
\hline Excessive user ( $\geq 60$ scores $)$ & 11(3.9) & - & - & - & - \\
\hline
\end{tabular}


sleeping hours a night). Among the participants, 55.3\% had completed their graduation from college and most of them did not have any part-time job (75.7\%) (Table 1).

None of the participants were classified as being addicted to internet (scoring $80+$ on the IAT), but $3.9 \%$ of the participants $(n=11)$ were classified as experiencing EIU (3.8\% males and $3.9 \%$ females). There were no significant differences regarding gender and excessive internet use $\left(X^{2}=0.002, \mathrm{df}=1, p=1.000\right)$. Among depressed participants, $7.8 \%$ were reported as excessive users compared to none of non-depressed participants $\left(X^{2}=11.606, \mathrm{df}=1\right.$, $p<0.0001)$. Among anxious participants, $4 \%$ were reported as excessive users compared to $3.8 \%$ of non-anxious participants $\left(X^{2}=0.009, \mathrm{df}=1, p=1.000\right)$. Among stressed participants, $10.7 \%$ were reported as excessive users compared to $1.4 \%$ of non-stressed participants $\left(X^{2}=\right.$ $12.633, \mathrm{df}=1, p<0.001)$. Most internet users $(94.7 \%)$ used the internet for less than $5 \mathrm{~h}$ daily, but $33.3 \%$ of excessive internet users spent more than $5 \mathrm{~h}$ daily compared to $2.2 \%$ of nonexcessive users $\left(X^{2}=36.915, \mathrm{df}=1, p<0.001\right)$ (Table 1$)$. A regression analysis was carried out, and depression (OR, 25.29; 95\% CI, 1.48-433.48, $p=0.026)$, stress (OR, 8.20; 95\% CI, $2.11-31.79, p=0.002)$, and engaging in more than $5 \mathrm{~h}$ online usage daily (OR, 21.92; $95 \% \mathrm{CI}$, 5.71-84.07, $p=0.001$ ) were found to be significant predictors of EIU (Table 2).

\section{Discussion}

Internet addiction (IA) has been researched since the mid-1990s, particularly in some Western and Asian countries, but not in developing countries such as Bangladesh, even though there has been a large increase in internet use over the past few years (Islam and Hossin 2016). This lack of knowledge about such an important issue could potentially hinder education and public health policymaking initiatives in the country (Lai and Kwan 2017). Consequently, the present study filled a knowledge gap regarding internet-related behaviors among recently graduated university students actively looking for a job in Rajshahi.

The present study found no individuals to be addicted to internet (i.e., scoring more than 80 out of 100 on the IAT) which is highly unusual and rare among studies examining IA, and appears to be very different to other Bangladeshi studies examining internet use (Mamun and Griffiths 2019b). This may be a consequence of the population studied (i.e., recent university graduates seeking full-time employment who appear to spend little time online because gaining full-time employment is the most important thing in their lives). It could be that jobseeking is a situational protective risk factor for developing IA. This is something that needs more formal empirical testing in studies both inside and outside of Bangladesh.

Although no-one was classed as having IA, 3.9\% of the participants $(n=11)$ were classified as excessive internet users (scoring more than 60 on the IAT). The present study's findings were similar to those reported in Karim and Nigar's study (Karim and Nigar 2014) who reported $1.74 \%$ if their student sample as being excessive internet users (IAT score > 62). However, the present findings are much lower than a previous survey among students in Dhaka, where nearly $24 \%$ of the participants in one study had IAT scores $\geq 50$ (Islam and Hossin 2016) using the reported IA of $48 \%$ (scoring over 80 on the IAT) (Uddin et al. 2016). This is much higher than a study of Bangladeshi high school students where $2.5 \%$ were classified as having severe IA and $64.87 \%$ having moderate IA using the Internet Addiction Survey (Afrin et al. 2017). The latter scale differs from the IAT because the response format (yes/no) is binary with nine questions, rather than using a continuous scale. A score of 7 or above (out of nine) is said to indicate severe internet addiction whereas a score of 3 indicates 
Table 2 Regression analysis of factors associated with excessive internet use

\begin{tabular}{|c|c|c|c|c|c|c|}
\hline \multirow[t]{2}{*}{ Variables } & \multicolumn{3}{|c|}{ Unadjusted model } & \multicolumn{3}{|l|}{ Adjusted model } \\
\hline & $\begin{array}{l}\text { Odds ratio } \\
(\mathrm{OR})\end{array}$ & $\begin{array}{l}95 \% \text { Confidence } \\
\text { interval }(\mathrm{CI})\end{array}$ & $\begin{array}{l}p \\
\text { value }\end{array}$ & $\begin{array}{l}\text { Adjusted odds } \\
\text { ratio (AOR) }\end{array}$ & $\begin{array}{l}95 \% \text { Confidence } \\
\text { interval }(\mathrm{CI})\end{array}$ & $\begin{array}{l}p \\
\text { value }\end{array}$ \\
\hline \multicolumn{7}{|l|}{ Gender } \\
\hline Male & 0.972 & $(0.290-3.262)$ & 0.972 & 0.884 & $(0.164-4.343)$ & 0.839 \\
\hline Female & Reference & & & Reference & & \\
\hline \multicolumn{7}{|l|}{ Permanent residence } \\
\hline Village area & 0.657 & $(0.168-2.563)$ & 0.546 & 0.659 & $(0.094-4.602)$ & 0.674 \\
\hline City area & Reference & & & Reference & & \\
\hline \multicolumn{7}{|l|}{ Relationship status } \\
\hline In a relationship & 0.869 & $(0.225-3.358)$ & 0.839 & 0.545 & $(0.088-3.362)$ & 0.514 \\
\hline Single & Reference & & & Reference & & \\
\hline \multicolumn{7}{|l|}{$\begin{array}{l}\text { Socio-economic } \\
\text { status of family }\end{array}$} \\
\hline Lower class & 1.340 & $(0.319-5.638)$ & 0.123 & 0.395 & $(0.063-2.978)$ & 0.106 \\
\hline Middle class & 0.290 & $(0.063-1.332)$ & & 0.074 & $(0.007-0.824)$ & \\
\hline Upper class & Reference & & & Reference & & \\
\hline \multicolumn{7}{|l|}{ Smoking status } \\
\hline Yes & 0.810 & $(0.100-6.551)$ & 0.843 & 0.354 & $(0.011-11.861)$ & 0.562 \\
\hline No & Reference & & & Reference & & \\
\hline \multicolumn{7}{|l|}{ Physical activities } \\
\hline Yes & 1.062 & $(0.274-4.112)$ & 0.931 & 1.162 & $(0.207-6.528)$ & 0.865 \\
\hline No & Reference & & & Reference & & \\
\hline \multicolumn{7}{|l|}{ Sleep quality } \\
\hline More than normal & 4.000 & $(0.432-37.054)$ & 0.328 & 2.082 & $(0.159-27.287)$ & 0.646 \\
\hline Normal $(6-7 \mathrm{~h})$ & 1.754 & $(0.206-14.916)$ & & 3.310 & $(0.253-43.307)$ & \\
\hline Less than normal & Reference & & & Reference & & \\
\hline \multicolumn{7}{|l|}{ Graduation institute } \\
\hline College & 1.435 & $(0.411-5.016)$ & 0.572 & 0.798 & $(0.155-4.112)$ & 0.787 \\
\hline University & Reference & & & Reference & & \\
\hline \multicolumn{7}{|c|}{ Current part-time job } \\
\hline Yes & 0.683 & $(0.144-3.241)$ & 0.632 & 0.488 & $(0.066-3.630)$ & 0.484 \\
\hline No & Reference & & & Reference & & \\
\hline \multicolumn{7}{|l|}{ Depression } \\
\hline Yes & 25.291 & $(1.476-433.477)$ & 0.026 & - & - & - \\
\hline No & Reference & & & - & - & - \\
\hline \multicolumn{7}{|l|}{ Anxiety } \\
\hline Yes & 1.059 & $(0.316-3.554)$ & 0.926 & 0.683 & $(0.127-3.662)$ & 0.656 \\
\hline No & Reference & & & Reference & & \\
\hline \multicolumn{7}{|l|}{ Stress } \\
\hline Yes & 8.199 & $(2.114-31.793)$ & 0.002 & 7.538 & $(1.422-39.975)$ & 0.018 \\
\hline No & Reference & & & Reference & & \\
\hline \multicolumn{7}{|l|}{$\begin{array}{l}\text { Online spent } \\
\text { time/day }\end{array}$} \\
\hline More than $5 \mathrm{~h}$ & 21.917 & $(5.714-84.066)$ & 0.000 & 65.512 & $(6.940-618.387)$ & 0.000 \\
\hline Less than $5 \mathrm{~h}$ & Reference & & & Reference & & \\
\hline
\end{tabular}

absence of addiction. An intermediate score from 4 to 6 indicates individuals have moderate internet addiction (Afrin et al. 2017).

A study conducted in six Asian countries using IAT with a cutoff score of 70 on the IAT reported the following prevalence rates: South Korea (14\%), China (19\%), Hong Kong (35\%), Malaysia (37.5\%), Japan (48\%), and Philippines (51\%) (Mak et al. 2014), whereas 14 to 55\% was suggested as problematic use in nine European countries (Laconi et al. 2018). A study of 
university adolescents comprising undergraduates and postgraduates in Nigeria reported an IA prevalence rate of $3.3 \%$ (scoring 70-100 on the IAT), whereas $20.3 \%$ were reported as being at risk of IA (scoring 50-70 on the IAT) (Adiele and Olatokun 2014). A study in Italy reported an IA prevalence rate of $12.1 \%$ among high school students (Vigna-Taglianti et al. 2017).

There may be several reasons explaining why no one in the present study was classed as being addicted to the internet. It may be possible there is less accessibility of the internet in Rajshahi (where the present study was conducted) compared to other areas of the country that may have more widespread access. Due to the pressure of job-seeking, participants may have had less time to spend on the internet compared to students. Another possibility may be that graduate job seekers were more aware of the negative consequences of EIU, and abstained from using the internet. Further studies are needed to identify the possible cause of the low prevalence of excessive internet use in this area of Bangladesh.

The present study showed no significant association between gender and EIU, which is in contrast to previous studies. Most have found males are more likely to experience internet addiction symptoms (e.g., Dieris-Hirche et al. 2017; Ostovar et al. 2016; Salehi et al. 2014; Younes et al. 2016) although the occasional study has found females to be more risk of IA (Afrin et al. 2017). Being single (e.g., unmarried, divorced, separated, widowed) has also been identified as a risk factor for IA but this was not found in the present study (although the majority of individuals in the present study were not in a relationship). Studies have also suggested a strong association between IA and poor sleep (Afrin et al. 2017; Bener et al. 2018; Bener and Bhugra 2013; Islam and Hossin 2016). However, the present study found no such association.

There is also a large body of research showing an association between IA and depressive disorders (e.g., Dalbudak et al. 2014; Dieris-Hirche et al. 2017; Ha et al. 2007; Ko et al. 2014; Mak et al. 2014; Ostovar et al. 2016) and other types of psychopathology (Carli et al. 2013). Similar to other behavioral addictions, addictive internet use often arises when individuals attempt to "self-treat" their stress, anxiety, and/or depression via excessive online activity (Allison et al. 2006; Khantzian 1997; Kuss et al. 2017). But, compared with other studies (Dalbudak et al. 2014; Dieris-Hirche et al. 2017; Ko et al. 2014; Mak et al. 2014; Ostovar et al. 2016), the present study did not show a significant relationship between anxiety and EIU. However, this may simply mean that excessive (as opposed to problematic) internet use is not associated with anxiety. In respect to psychopathology, depression and stress were risk factors for excessive internet use in the present study, and were therefore similar to previous research (e.g., Dieris-Hirche et al. 2017; Ostovar et al. 2016; Younes et al. 2016).

Spending more hours using the internet was predictably found to increase the risk of excessive internet use. Using the internet more than $5 \mathrm{~h}$ daily has been designated as an important risk factor for IA although excessive use can simply be a function of educational and/or occupational activity (Griffiths 2010; Laconi et al. 2018; Salehi et al. 2014) and on its own is not necessarily an indicator of problematic use (and excessive use is also not necessarily problematic). Young (2007) suggested that using the internet for more than $38 \mathrm{~h}$ a week may result in addiction, similar to Bener et al. (2018) who suggested $35 \mathrm{~h}$ a week. However, such simple time indicators have been criticized as not taking the context of internet use into account (Griffiths 2010).

\section{Implications}

No one was classed as addicted to the internet in the present study, and the rate of EIU was lower compared to other comparable studies. However, some of the excessive users may be 
more at risk of developing IA and need to be educated about the fact that for a minority of users, excessive internet use can lead to physical and psychological distress and impairment (Bener and Bhugra 2013; Ko et al. 2014). In the present study, the levels of psychopathology were high across the total sample — depression (49.6\%), anxiety (53.2\%), and stress (26.4\%) which in other studies have shown to be associated with IA. However, these high levels of psychopathology might also be related to the fact that the sample was not in full-time employment which is likely to cause depression and anxiety leading to increased stress levels (or vice-versa). It should also be noted that the DASS is not a diagnostic instrument but that does not mean that such symptoms of depression, anxiety, and stress are not real and may still require attention from health care professionals (Bayram and Bilgel 2008; Shamsuddin et al. 2013). Therefore, the mental support centers and public awareness programs in Bangladesh are needed to help reduce problems related to excessive internet use.

\section{Limitations}

The present study is not without limitations. First, it is limited by the use of self-reported data which might have influenced the results through method biases, social desirability biases, and memory recall biases. Second, due to the cross-sectional nature of the study, no conclusions can be drawn regarding causality. The study is also limited by the relatively small sample size and study location (Rajshahi), so the generalization of the whole country (and other countries) is highly limited. Future studies need to overcome such limitations by employing longitudinal designs with larger and more representative samples (although further studies examining recent university graduates seeking jobs are also warranted given that no cases of IA were found in the present study).

\section{Conclusions}

In conclusion, the present study presented some baseline data (i.e., prevalence, risk factors regarding excessive internet use among recent university graduate students who were seeking jobs in Rajshahi city), where no previous data in the country had ever been collected. Predictably, the findings showed that behavioral indicators such as spending more than $5 \mathrm{~h}$ daily online and unhealthy psychological mental states (e.g., stress) are associated with excessive internet use. The findings suggest that educational and prevention initiatives are needed in Bangladesh regarding the mental wellbeing of students following their graduation in relation to the detrimental consequences of problematic internet use as well as psychiatric symptoms of depression, anxiety, and stress which can be associated with it.

\section{Compliance with Ethical Standards}

Conflict of Interest The authors declare that they do not have any interests that could constitute a real, potential or apparent conflict of interest with respect to their involvement in the publication. The authors also declare that they do not have any financial or other relations (e.g. directorship, consultancy or speaker fee) with companies, trade associations, unions or groups (including civic associations and public interest groups) that may gain or lose financially from the results or conclusions in the study. Sources of funding are acknowledged.

Ethical Approval All procedures performed in this study involving human participants were in accordance with the ethical standards of University's Research Ethics Board and with the 1975 Helsinki Declaration. 
Informed Consent Informed consent was obtained from all participants.

Open Access This article is distributed under the terms of the Creative Commons Attribution 4.0 International License (http://creativecommons.org/licenses/by/4.0/), which permits unrestricted use, distribution, and reproduction in any medium, provided you give appropriate credit to the original author(s) and the source, provide a link to the Creative Commons license, and indicate if changes were made.

\section{References}

Adiele, I., \& Olatokun, W. (2014). Prevalence and determinants of internet addiction among adolescents. Computers in Human Behavior, 31, 100-110.

Afrin, D., Islam, M.-U., Rabbiand, F., \& Hossain, A. (2017). The school-level factors associated with internet addiction among adolescents: A cross-sectional study in Bangladesh. Journal of Addiction and Dependence, 3(2), 170-174.

Alim, S. M. A. H. M., Rabbani, M. G., Karim, E., Mullick, M. S. I., Al Mamun, A., \& Khan, M. Z. R. (2017). Assessment of depression, anxiety and stress among first year MBBS students of a public medical college, Bangladesh. Bangladesh Journal of Psychiatry, 29(1), 23-29.

Allison, S. E., von Wahlde, L., Shockley, T., \& Gabbard, G. O. (2006). The development of the self in the era of the internet and role-playing fantasy games. American Journal of Psychiatry, 163(3), 381-385.

Bayram, N., \& Bilgel, N. (2008). The prevalence and socio-demographic correlations of depression, anxiety and stress among a group of university students. Social Psychiatry and Psychiatric Epidemiology, 43(8), 667-672.

Begum, A., Rahman, A. F., Rahman, A., Soares, J., Reza Khankeh, H., \& Macassa, G. (2017). Prevalence of suicide ideation among adolescents and young adults in rural Bangladesh. International Journal of Mental Health, 46(3), 177-187.

Bener, A., \& Bhugra, D. (2013). Lifestyle and depressive risk factors associated with problematic internet use in adolescents in an Arabian Gulf culture. Journal of Addiction Medicine, 7(4), 236-242.

Bener, A., Yildirim, E., Torun, P., Çatan, F., Bolat, E., Alıç, S., ... Griffiths, M. D. (2018). Internet addiction, fatigue, and sleep problems among adolescent students: A large-scale study. International Journal of Mental Health and Addiction. https://doi.org/10.1007/s11469-018-9937-1.

Bangladesh Telecommunication Regulatory Commission (2018). Internet | Bangladesh Telecommunication Regulatory Commission. Retrieved December 3, 2018, from http://www.btrc.gov.bd/telco/internet .

Carli, V., Durkee, T., Wasserman, D., Hadlaczky, G., Despalins, R., Kramarz, E., Wasserman, C., Sarchiapone, M., Hoven, C.W., Brunner, R., \& Kaess, M. (2013). The association between pathological internet use and comorbid psychopathology: A systematic review. Psychopathology, 46(1), 1-13.

Dalbudak, E., Evren, C., Aldemir, S., \& Evren, B. (2014). The severity of internet addiction risk and its relationship with the severity of borderline personality features, childhood traumas, dissociative experiences, depression and anxiety symptoms among Turkish university students. Psychiatry Research, 219(3), 577-582.

Dieris-Hirche, J., Bottel, L., Bielefeld, M., Steinbüchel, T., Kehyayan, A., Dieris, B., \& te Wildt, B. (2017). Media use and internet addiction in adult depression: A case-control study. Computers in Human Behavior, 68, 96-103.

Griffiths, M. (1996). Behavioural addiction: An issue for everybody? Employee Councelling Today, 8(3), 19-25.

Griffiths, M. D. (1998). Internet addiction: Does it really exist? In J. Gack (Ed.), In Psychology and the Internet: Intrapersonal, interpersonal, and transpersonal implications (pp. 61-75). San Diego: Academic Press.

Griffiths, M. (2005). A 'components' model of addiction within a biopsychosocial framework. Journal of Substance Use, 10(4), 191-197.

Griffiths, M. D. (2010). The role of context in online gaming excess and addiction: some case study evidence. International Journal of Mental Health and Addiction, 8(1), 119-125.

Ha, J. H., Kim, S. Y., Bae, S. C., Bae, S., Kim, H., Sim, M., \& Cho, S. C. (2007). Depression and internet addiction in adolescents. Psychopathology, 40(6), 424-430.

Hoare, E., Milton, K., Foster, C., \& Allender, S. (2017). Depression, psychological distress and internet use among community-based Australian adolescents: A cross-sectional study. BMC Public Health, 17(1), 365.

Islam, M. A., \& Hossin, M. Z. (2016). Prevalence and risk factors of problematic internet use and the associated psychological distress among graduate students of Bangladesh. Asian Journal of Gambling Issues and Public Health, 6(1), 1-11.

Karim, A. K. M. R., \& Nigar, N. (2014). The internet addiction test: Assessing its psychometric properties in Bangladeshi culture. Asian Journal of Psychiatry, 10, 75-83. 
Khantzian, E. J. (1997). The self-medication hypothesis of substance use disorders: A reconsideration and recent applications. Harvard Review of Psychiatry, 4(5), 231-244.

Ko, C.-H., Liu, T.-L., Wang, P.-W., Chen, C.-S., Yen, C.-F., \& Yen, J.-Y. (2014). The exacerbation of depression, hostility, and social anxiety in the course of internet addiction among adolescents: A prospective study. Comprehensive Psychiatry, 55(6), 1377-1384.

Kuss, D. J., D Griffiths, M., Karila, L., \& Billieux, J. (2014). Internet addiction: A systematic review of epidemiological research for the last decade. Current Pharmaceutical Design, 20(25), 4026-4052.

Kuss, D. J., Dunn, T. J., Wölfling, K., Müller, K. W., Hędzelek, M., \& Marcinkowski, J. (2017). Excessive internet use and psychopathology: the role of coping. Clinical Neuropsychiatry: Journal of Treatment Evaluation, 14(1), 73-81.

Laconi, S., Kaliszewska-Czeremska, K., Gnisci, A., Sergi, I., Barke, A., Jeromin, F., Groth, J., Gamez-Guadix, M., Ozcan, N.K., Demetrovics, Z., \& Király, O. (2018). Cross-cultural study of problematic internet use in nine European countries. Computers in Human Behavior, 84, 430-440.

Lai, F. T. T., \& Kwan, J. L. Y. (2017). Socioeconomic influence on adolescent problematic Internet use through school-related psychosocial factors and pattern of Internet use. Computers in Human Behavior, 68, 121-136.

Lee, T. K., Roh, S., Han, J. H., Park, S. J., Soh, M. A., Han, D. H., \& Shaffer, H. J. (2016). The relationship of problematic internet use with dissociation among South Korean internet users. Psychiatry Research, 241, 66-71.

Lovibond, P. F., \& Lovibond, S. H. (1995). Manual for the depression anxiety stress scales (2nd ed.). Sydney: Psychology Foundation.

Mak, K.-K., Lai, C.-M., Watanabe, H., Kim, D.-I., Bahar, N., Ramos, M., et al. (2014). Epidemiology of internet behaviors and addiction among adolescents in six Asian countries. Cyberpsychology, Behavior and Social Networking, 17(11), 720-728.

Mamun, M. A. A., \& Griffiths, M. D. (2019a). The association between Facebook addiction and depression: A pilot survey study among Bangladeshi students. Psychiatry Research, 271, 628-633.

Mamun, M. A., \& Griffiths, M. D. (2019b). The assessment of internet addiction in Bangladesh: why are prevalence rates so different? Asian Journal of Psychiatry, 40, 46-47.

Ostovar, S., Allahyar, N., Aminpoor, H., Moafian, F., Nor, M. B. M., \& Griffiths, M. D. (2016). Internet addiction and its psychosocial risks (depression, anxiety, stress and loneliness) among Iranian adolescents and young adults: A structural equation model in a cross-sectional study. International Journal of Mental Health and Addiction, 14(3), 257-267.

Salehi, M., Khalili, M. N., Hojjat, S. K., Salehi, M., \& Danesh, A. (2014). Prevalence of internet addiction and associated factors among medical students from Mashhad, Iran in 2013. Iranian Red Crescent Medical Journal, 16(5), e17256.

Shamsuddin, K., Fadzil, F., Ismail, W. S. W., Shah, S. A., Omar, K., Muhammad, N. A., Jaffar, A., Ismail, A., \& Mahadevan, R. (2013). Correlates of depression, anxiety and stress among Malaysian university students. Asian Journal of Psychiatry, 6(4), 318-323

Simcharoen, S., Pinyopornpanish, M., Haoprom, P., Kuntawong, P., Wongpakaran, N., \& Wongpakaran, T. (2018). Prevalence, associated factors and impact of loneliness and interpersonal problems on internet addiction: A study in Chiang Mai medical students. Asian Journal of Psychiatry, 31, 2-7.

Uddin, M. S., Al Mamun, A., Iqbal, M. A., Nasrullah, M., Asaduzzaman, M., Sarwar, M. S., \& Amran, M. S. (2016). Internet addiction disorder and its pathogenicity to psychological distress and depression among university students: A cross-sectional pilot study in Bangladesh. Psychology, 7(08), 1126-1137.

Vigna-Taglianti, F., Brambilla, R., Priotto, B., Angelino, R., Cuomo, G., \& Diecidue, R. (2017). Problematic internet use among high school students: Prevalence, associated factors and gender differences. Psychiatry Research, 257, 163-171.

Younes, F., Halawi, G., Jabbour, H., El Osta, N., Karam, L., Hajj, A., \& Khabbaz, L. R. (2016). Internet addiction and relationships with insomnia, anxiety, depression, stress and self-esteem in university students: A crosssectional designed study. PLoS One, 11(9), e 0161126.

Young, K. S. (1998). Internet addiction: the emergence of a new clinical disorder. Cyberpsychology \& Behavior, 1(3), 237-244.

Young, K. S. (2007). Cognitive behavior therapy with internet addicts: Treatment outcomes and implications. CyberPsychology \& Behavior, 10(5), 671-679.

Publisher's Note Springer Nature remains neutral with regard to jurisdictional claims in published maps and institutional affiliations. 